Schizophrenics comprise a very heterogeneous group, and patients present with very different patterns of symptoms. There are probably more than several neuropsychological defects that give rise to different symptoms, and it is no wonder that no one theory can explain them all. All may be correct. Drs Frith and Done are on the right track in linking the symptoms of schizophrenia with neuropsychological theories and findings of malfunction in specific brain systems. One day it will lead us somewhere.

South Kwai Chung Psychiatric Centre

South Kwai Chung Jockey Club Polyclinic

Kwai Chung

Kowloon

Hong Kong

\section{Naltrexone and Clonidine in Heroin Withdrawal Treatment}

SIR: We noted with interest Brewer et al's study of naltrexone and clonidine in the treatment of opioid withdrawal (Journal, September 1988, 153, 340-343). The search for a rapid and effective treatment for opioid withdrawal has been in progress for many years (Kolb \& Himmelsbach, 1938). A treatment which promises to reduce the length of detoxification to less than three days with minimal drop-out will clearly appeal to many clinicians working in this field. We suggest, however, that the claims made by the authors are overstated and not supported by the results of the present study.

The authors state that the treatment was of "high acceptability" to patients. No evidence is put forward in support of this view such as patient's reports of acceptability or even an assessment of subjective symptoms or objective signs of opiate withdrawal. Furthermore, the treatment described was not compared with any other more commonly available treatment such as methadone or clonidine, leaving the authors' claims of effectiveness open to question.

Opiate withdrawal is now recognised to be subject to the influence of psychological factors including expectancy (Phillips et al, 1986). Thus, it is essential to conduct studies in double-blind design (Drummond et al, 1989), otherwise highly misleading results may be obtained.

The authors describe their treatment as the "naltrexone-clonidine technique". Closer examination of the method, however, reveals that in addition, patients received diazepam, nitrazepam, flurazepam, and hyoscine. This latter treatment was prescribed for "troublesome" abdominal cramping and nausea which were clearly not relieved by the naltrexoneclonidine combination. Furthermore, the dose of diazepam prescribed (up to $180 \mathrm{mg}$ per day) was considerably higher than in studies of benzodiazepines used alone in the treatment of heroin withdrawal. Indeed, some subjects "experienced significant discomfort". This suggests that the basic naltrexoneclonidine combination was ineffective in controlling opioid withdrawal. The question arises as to whether any one of the drugs used in this combination regime would have been effective if taken alone in a sufficient dose. In a recent double-blind trial we found that cholordiazepoxide ( $250 \mathrm{mg}$ daily) was as effective in controlling subjective withdrawal symptoms as a conventional methadone detoxification regimen (Drummond et al, 1989). The authors postulate that the mechanism of action of naltrexone in opioid withdrawal is that it "rapidly normalises the number and sensitivity of opiate receptors and reversed opioid induced central noradrenergic activity". While this tempting speculation adds a sense of scientific validity to the treatment, it is not supported either by evidence in this study or in the study cited in support of it (Kleber et al, 1987).

The authors suggest that the results of this study have "major implications" for National Health Service (NHS) treatment programmes, and question the need for specialist detoxification units and indeed specialised training in psychiatry or the addictions. To suggest that a highly selected group of private patients with major financial incentives for treatment is comparable to attenders at an NHS drug clinic or general practice is erroneous. Second, home withdrawal "with the help of telephoned instructions, a visiting nurse or an electronic sphygmomanometer" in our view hardly constitutes comprehensive treatment, represents a narrow view of the problem of heroin addiction, and does not amount to good value for money.

In a review of the early history of detoxification treatments, Klob \& Himmelsbach (1938) observed "new treatments said to be specific [for heroin withdrawal] are advanced from time to time and then discarded as useless or even harmful". Champions of the naltrexone-clonidine technique would be well advised to subject this treatment to proper scientific scrutiny before making such assertions about its effectiveness. The methodology for such an investigation has been in existence for nearly half a century.

Addiction Research Unit

D. Colin Drummond

Institute of Psychiatry

London SE5 $8 A F$

Bassetlaw District General Hospital

DOUGLAS TURKINGTON

Nottinghamshire 


\section{References}

Drummond, D. C., Turkington, D., Rahman, M. Z. et al (1989) Chlordiazepoxide vs methadone in heroin withdrawal. Drug and Alcohol Dependence (in press).

Kleber, H. D., Topazian, M., Gaspari, J., et al (1987) Clonidine and naltrexone in the outpatient treatment of heroin withdrawal. American Journal of Drug and Alcohol Abuse, 13, 1-17.

Kolb, L. \& Himmelsbach, C. K. (1938) Clinical studies of drug addiction, III: a critical review of withdrawal treatments with method of evaluating abstinence syndromes. American Journal of Psychiatry, 94, 759-797.

Phillips, G. T., Gossop, M. \& Bradley, B. (1986) The influence of psychological factors on the opiate withdrawal syndrome. British Journal of Psychiatry, 149, 235-238.

SIR: Drs Drummond and Turkington have averaged one error of fact or interpretation for each of their six paragraphs. It is true that we did not cite the evidence for our claim of "high acceptability", but there are several free withdrawal programmes available to opiate addicts in London. That patients or their families were evidently prepared to pay for our programme, even though we now also offer out-patient methadone withdrawal, surely indicates a fairly high level of acceptability. Currently, over $80 \%$ of our withdrawal patients are selfreferred.

The authors evidently believe our patients to be relatively affluent and unrepresentative. In reality, the large majority are from social class 3 or lower. Many are unemployed at the time of admission. One of the main reasons for speeding up the withdrawal process is that it reduces the cost. By further modifying our techniques, we can now discharge our patients after only 24 hours in most cases at a cost as low as $£ 325$. Even relatively poor families can often afford this sort of figure.

More importantly, Drs Drummond and Turkington seem to have overlooked the fact that the title of the paper is "Opioid withdrawal and naltrexone induction ...", and that this technique is not simply a method of helping opioid addicts to stop taking opioids. It is also a method of getting them started on a drug which greatly reduces the risk of relapse (Brahen et al, 1984) without the usual delay of five to ten days after withdrawal when the risk of relapse is particularly high. In Drs Drummond and Turkington's own study, only $37 \%$ of their patients achieved drug-free status after 14 days, and several discharged themselves prematurely.

Objective measures of withdrawal symptoms would have been a useful addition to our study, but they are of less practical importance than whether or not a significant proportion of patients withdrawn using this technique continue to abstain from opiates after discharge. Whichever withdrawal technique is used, many addicts will report persisting discomfort, sometimes for weeks or even months after they have been officially 'withdrawn'. The preliminary results of a follow-up of our recent patients echo the findings of Brahen et al (1984) and others that provided naltrexone administration is supervised by a third party (usually a family member), early drop-out levels are low. Fewer than $10 \%$ appear to discontinue naltrexone during the first week. The value of supervision in preventing relapse is supported by studies of supervised disulfiram in the treatment of alcohol abuse, which involves similar concepts (Brewer, 1987). We did not compare our technique with other withdrawal methods using clonidine or methadone alone, but as we pointed out, others have already done so (Charney et al, 1986) and have found that clonidinenaltrexone comes out well.

Finally, although in a few cases the total diazepam dose for the first 24 hours exceeded the equivalent of the maximum daily chlordiazepoxide dose used by Drs Drummond and Turkington, most of our patients used considerably less. Furthermore, we prescribed daytime benzodiazepines for only two to three days, so that our total benzodiazepine dosage was very considerably lower than theirs. In our present 24-hour detoxification and naltrexone-induction programme, the total benzodiazepine dose is even less, further supporting our finding that speeding up the withdrawal process reduces the overall requirement for supplementary medication. Thus the suggested mechanism of rapid normalisation of opiate receptor sensitivity is indeed supported by our study and by our subsequent experience. However, I regret that in trying to be concise we inadvertently gave the impression that this theory originated with Kleber et al (1987), rather than with some of the studies cited in their paper.

\section{The Stapleford Unit \\ London Road \\ Stapleford Tawney}

Essex RM4 1SR

\section{References}

Brahen, L. S., Henderson, R. K., Capone, T., el al (1984) Naltrexone treatment in a jail work-release programme. Journal of Clinical Psychiatry, 45, 49-52.

BREWER, C. (1987) Naltrexone: an Antabuse for heroin addicts. Pharmaceutical Journal, 15 August, 182-183.

Charney, D. S., Heninger, G. R. \& Kleber, H. (1986) The combined use of clonidine and naltrexone as a safe, rapid and effective treatment of abrupt withdrawal from methadone. American Journal of Psychiatry, 143, 831-837.

Kleber, H. D., Topazian, M., Gaspari, J., et al (1987) Clonidine and naltrexone in the out-patient treatment of heroin withdrawal. American Journal of Drug and Alcohol Abuse, 13, $1-17$. 